\title{
Frequency of Ectasia among Patients with Coronary Atherosclerosis by Angiography Dual Source \& 64 CT SLICE Evaluatin
}

\author{
Marzie Motevalli ${ }^{1}$, Mohammad Jalali ${ }^{2}$, Raheleh Najarian ${ }^{3}$, Fahimeh Rahnama ${ }^{4}$, Shahrooz Yazdani ${ }^{5}$ \\ ${ }^{1}$ Associate professor Shahid rajaie cardiovascular medical and research center department \\ ${ }^{2}$ Assistant Professor of Cardiology School of Medicine Alborz university of medical sciences \\ ${ }^{3}$ Emergency medicin specialist \\ ${ }^{4}$ Radiologist alborz university of medical sciences \\ ${ }^{5}$ Assistant Professor of Cardiology School of Medicine Alborz university of medical sciences \\ Correspondence: Mohammad Jalali, Cardiology School of Medicine Alborz university of medical sciences. Email: \\ mdrjalali602@gmail.com
}

Received: December 7, 2019

Accepted: January 14, 2020

Online Published: March 30, 2020

doi:10.5539/jmbr.v10n1p24

URL: https://doi.org/10.5539/jmbr.v10n1p24

\begin{abstract}
Introduction: The aim of this study is Frequency of ectasia among patients with coronary atherosclerosis. Materials and Methods: This is a cross-sectional study, which retrospectively had evaluated a percentage of total frequency ectasia among patients with coronary atherosclerosis by angiography Dual a source \& 64 CT SLICE between 2007-20012 in Imag Center of Imam Khomeini Hospital and shahid Rajai Hospital.

Results: Totally 2770 patients were enrolled in the study. The frequency of ectasia among all patients was 42 [1.5\%]. The frequency of stenosis in patients with LAD ectasia was $36.8 \%$ [7 out of 19] while the frequency of LAD stenosis in other patients was 59.5\% [1637 out of 2751] [P=0.045]. Distribution of stenosis in ecstatic LCx and RCA was not statistically different with patients without non ecstatic LCx and RCA. $[\mathrm{P}=0.47$ and 0.45 respectively]. In patients with ectasia, the frequency of stenosis was 71.4 while it was $64.4 \%$ in patients without ectasia $[\mathrm{P}=0.35]$.

Discussion: Furthermore, detection and investigation of Ectasia in patients with stenosis will lead to more accurate determination of the treatment plan and the purpose of this study is finging a new assess prevalence of morphological changes Ectasia by CT angiography and coronary sclerosing Prevalence this group of patients.
\end{abstract}

Keywords: Ectasia, Coronary Atherosclerosis, Angiography Dual Source \& 64 CT SLICE

\section{Introduction}

Coronary-related disease is one of the common diseases (Liu-qiang et al., 2017). Many Ectasia coronary means uncommon dilatation in coronary artery, Ectasia coronary incidence is about 1\%-5\%. Some levels of spasticity, cardiac ischemia, thrombosis and coronary artery dissection and rupture in patients with Ectasia were more reprted. So, it is important to diagnose coronary artery Ectasia for antiplatelet therapy to reduce surgical complications.

Recent advances in CT angiography can be increased diagnosis of coronary artery disease. Today, this common method is used for the detection of coronary artery stenosis in patients who suspected of low or moderate corner disease.

Despite these advances, very few papers had been investigated about Ectasia diagnostic coronary by CT angiography. The aim of this study is Frequency of ectasia among patients with coronary atherosclerosis.

\section{Materials and Methods}

This is a cross- sectional study by census sampling, which retrospectively had evaluated a percentage of total frequency ectasia among patients with coronary atherosclerosis by angiography Dual source \& 64 CT SLICE between 2007-2012 in Imam Khomeini Hospital and shahid Rajai Hospital.

All CT angiography had been done by 64-slice GE Light speed VCT models, and Siemens Dual source FLASH model. Patient's heart rate should not be higher than 70 during CT angiography so, in the absence of contraindications, beta-blockers were used, too. Dualsource be injected for all patients (by a isosorbidnitrate dose). 
This dose was adjusted based on each specific time (CT) and BMI Rate of $5 \mathrm{ml}$ per second, followed by a mixture of contrast and saline injection. CT in the Cardio-caudal level of the carina to the diaphragm was performed, too.

ECG was done for all patients and images were taken in all phases of systole and diastole. ( $0 \%$ to $90 \%$ Sytsvl and diastole). Images MRP, MIP, VRT done for all patients, so, Ectasia and stenosis in all images had been reviewd and evaluated. Time fore image examination in 64-slice device was 10-12 minutes and for Dual source device was 4-8 minutes.

\section{How to Calculate CT Angiography}

An observer had measured of maximum diameter for each Ectasia segment. It also differs in size from the diameter of a normal segment was also calculated.Ectasia ratio (diameter segment of Ectasia/segment average according to normal diameter) was calculated. Aneurysm Ectasia was defined by a ratio in two groups with a ratio of 1.5 up to 2 and 2 or more. Descriptive analysis was used to evaluate the frequency Ectasia (percentage of total stereotypes) and frequency separately of each gender and coronary artery disease. $95 \%$ confidence intervals were estimated and the results are presented in tables and graphs.

\section{Results}

Totally 2770 patients were enrplled in the study. The mean age of the patients was $57.1 \pm 12.5$ [7-93] years. Totally, 1652 were male [59.6\%] we assessed the number and frequency of ectasia in terms of each coronary artery and in sub segments of main coronary artery. There was 12 ectatic left main amang the patients [0.43\%] The frequency of ectasia in LAD, LCx and RCA were 19, 12 and 24 amang the patients.

Detailed frequency of ectasia in coronary subsegments have been mentioned in Table 1.

Table 1.

\begin{tabular}{|c|c|c|c|c|c|}
\hline \multirow{2}{*}{ Coronary Artery } & \multirow{2}{*}{ Number [\%] } & \multirow{2}{*}{ Coronary subsegment } & \multirow{2}{*}{ Number [\%] } & \multicolumn{2}{|c|}{ Gender } \\
\hline & & & & Male & Female \\
\hline LM & $12[0.43]$ & & $12[0.43]$ & 10 & 2 \\
\hline \multirow{6}{*}{ LAD } & \multirow{6}{*}{$19[0.69]$} & Proximal portion & $17[061]$ & 14 & 3 \\
\hline & & Middle portion & $5[0.18]$ & 4 & 1 \\
\hline & & Distal portion & $2[0.07]$ & 1 & 1 \\
\hline & & Ramus intermedius & $1[0.04]$ & 1 & 0 \\
\hline & & D1 & $3[0.11]$ & 2 & 1 \\
\hline & & D2 & $1[0.04]$ & 1 & 0 \\
\hline \multirow{5}{*}{$\mathrm{LCx}$} & \multirow{5}{*}{$12[0.43]$} & Proximal portion & $6[0.22]$ & 4 & 2 \\
\hline & & Middle portion & $9[0.32]$ & 5 & 4 \\
\hline & & Distal portion & $3[0.11]$ & 2 & 1 \\
\hline & & OM1 & $4[0.14]$ & 3 & 1 \\
\hline & & OM2 & $3[0.11]$ & 3 & 0 \\
\hline \multirow{6}{*}{$\mathrm{RCA}$} & \multirow{6}{*}{$24[0.87]$} & Proximal portion & $15[0.54]$ & 11 & 4 \\
\hline & & Middle portion & $12[0.43]$ & 11 & 1 \\
\hline & & Distal portion & $12[0.43]$ & 11 & 1 \\
\hline & & RVB & 0 & 0 & 0 \\
\hline & & PDA & $3[0.11]$ & 3 & 0 \\
\hline & & PLV & 0 & 0 & 0 \\
\hline
\end{tabular}

The frequency of ectasia among all patients was 42 [1.5\%].

The frequency of stenosis in patients with LAD ectasia was 36.8\% [7 out of 19] while the frequency of stenosis in other patients was $59.5 \%$ [1637 out of 2751] [P=0.045].

Distribution of stenosis in ecstatic LCx and RCA was not ststistically different with patients without non ecstatic LCx and RCA. [P=0.47 and 0.45 respectively]. 


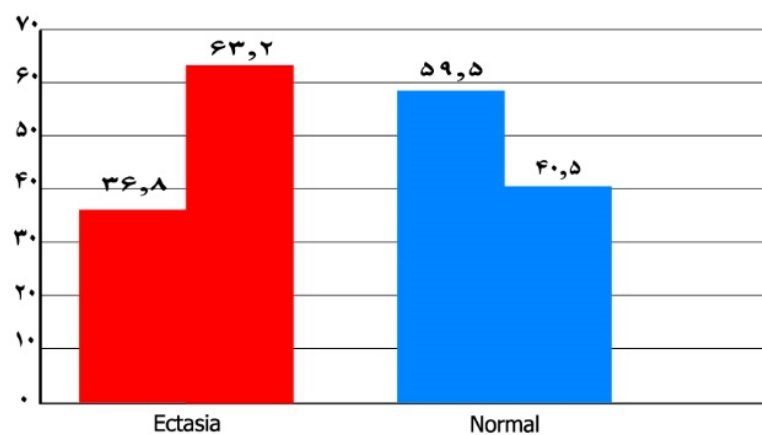

Stenosis

Normal

Figure 1. Correlation of Ectasia and Stenosis in LAD

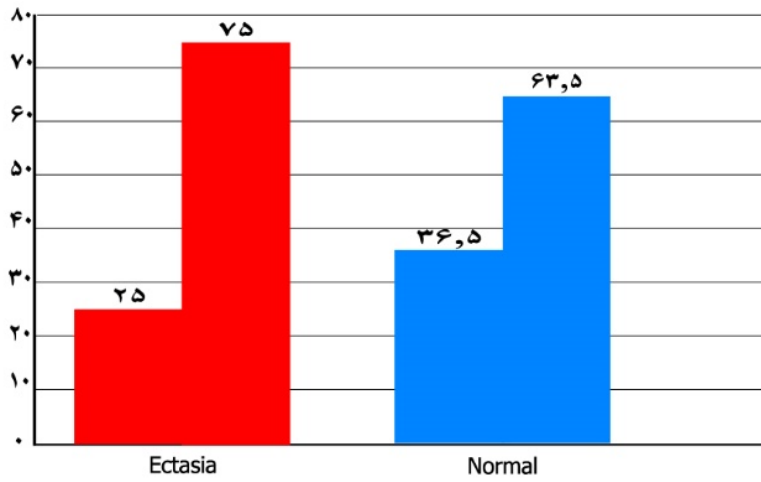

Stenosis

Normal

Figure 2. Correlation of Ectasia and Stenosis in LCx

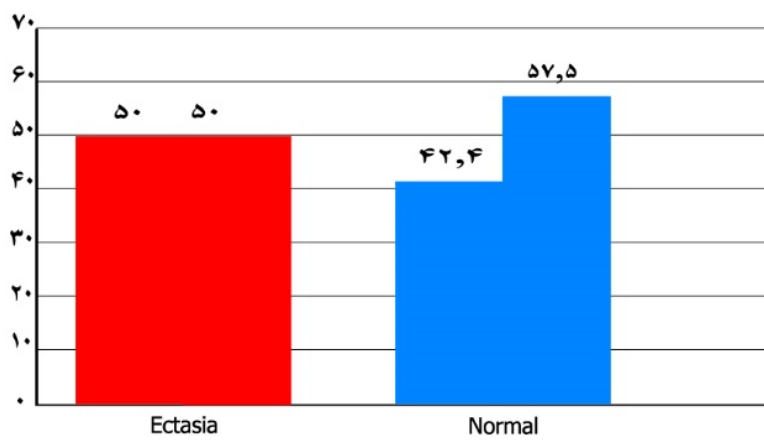

Stenosis

Normal

Figure 3. Correlation of Ectasia and Stenosis in RCA

Inpatients with ectasia, the frequency of stenosis was 71.4 while it was $64.4 \%$ in patients without ectasia [P=0.33].

\section{Discussion}

Coronary Ectasia more than two centuries has been observed by pathologists and cardiologists. (Falestti \& Carrol, 1976)

First described by Morgagni et Ectasia was conducted in 1761. Deaud and colleagues in patients older than 16 years reported a prevalence of $1.4 \%$ for Coronary Ectasia. (Daoud, Pankin, Tulgan, \& Floretin, 1963). 1\%-5\% Of Ectasia have been reported in other articales. In our study, totally, 1652 were male [59.6\%] we assessed the number and frequency of ectasia in terms of each coronary artery and in sub segments of main coronary artery. There was 12 ectatic left main amang the patients.

Although these rates may be higher than the incidence in the normal population. In the largest study by Sway and colleagues in CASS Registration, the prevalence of Ectasia in 200,000 cases was 4.9\% (Sway et al., 1983) The clinical significance of coronary Ectasia there is conflicting evidence. In some articales, not to mention the 
difference in prognosis in this group of patients is normal (Sway et al., 1983) and in some articales, Ectasia had no effect on coronary artery bypass grafts has been mentioned. (Alford Jr, Stoney, Burrus, First, \& Thomas Jr, 1976) In the large number of papers, it was mentioned that non-uniformity prognosis of this group. One of these items are increase the amount of spasms (Suzuki et al., 1994), exercise-induced cardiac ischemia (Kruger, Stierle, Herrmann, Simon, \& Sheikhazadeh, 1999), thrombosis (Perlman \& Ridgewey, 1989), and dissection (Myerburge, 1991) and coronary artery rupture (Satoda, Tatsukawa, \& Katoh, 1998). And the detection of coronary artery Ectasia was important and complications. (Ramappa, Kottam, Kuivanemi, \& Thatai, 2007) Also have some sources mention that Ectasia coronary is important as coronary stenosis artery size (Herman \& Gorlin, 1976). Several studies are shown that CT angiography is a noninvasive approach for of coronary artery disease diagnosis, and also, angiography as a noninvasive method for precise determination of coronary artery variants can be used, too. (Kosar, Ergun, Ozturk, \& Kosar, 2009) For example, in a retrospectively study that conducted in Turkey by Koser and colleagues, is shown that CT angiography in 700 patients with suspected coronary artery disease were examined and different variants were investigated, resulting in coronary CT angiography as a noninvasive method for precise determination of coronary artery variants can be used. (Kosar, Ergun, Ozturk, \& Kosar, 2009)

Accourding our study, the frequency of ectasia among all patients was 42 [1.5\%]. The frequency of stenosis in patients with LAD ectasia was $36.8 \%$ [ 7 out of 19] while the frequency of LAD stenosis in other patients was 59.5\% [1637 out of 2751] [P=0.045].

In patients with proximal and middle segments of coronary artery disease, right Corner is most commonly involved segments for ectasia, and then left descending and rotation coronary artery is the second segment for ectasia incidence. (Demopoulos et al., 1997)

Distribution of stenosis in ecstatic LCx and RCA was not statistically different with patients without non ecstatic LCx and RCA. [ $\mathrm{P}=0.47$ and 0.45 respectively]

In Iran, few studies have examined the coronary Ectasia different variants. In the case study reported by Hashmi et al reported a case of aneurysm of the report has been expanded with a septal hypertrophy. (Petrossians, 1993)

In our study, In patients with ectasia, the frequency of stenosis was 71.4 while it was $64.4 \%$ in patients without ectasia $[\mathrm{P}=0.35]$.

In another case reported by Leach and colleagues conducted a case of the left main coronary artery stenosis that diagnosed with a mass in the right atrium diagnosis by computed tomography (Safi et al., 2009).

In another retrospectively study was conducted by the AKSU and colleagues 12514 coronary angiography were examined and then compared. The prevalence of Ectasia was 1.59\%.

Ectasia incidence in the cohort study that conducted in India by Sharma and colleagues was $10 \%$ in patients with ischemia. (Sharma et al., 1990) According to the results of this study, it be suggested, Future studies, it is need to examine the relationship Ectasia coronary atherosclerosis in prospective studies with larger sample size.

\section{Conflict of interests}

The authors declare that there is no conflict of interests regarding the publication of this paper.

\section{References}

Aksu et al. (2011). Coronary artery ectasia: Its frequency and relationship with atherosclerotic risk factors in patiets undergoing cardiac catheterization. Anadolu kardiyol Derg, 4, 280.

Alford Jr, W. C., Stoney, W. S., Burrus, G. R., First, R. A., \& Thomas Jr, C. S. (1976). Recognition and Operative Management of patients with atherosclerotic coronary artery aneurysms. The Annals of Thoracic Surgery, 22(4), 317-21.

Budoff et al. (2006). Assessment of coronary artery, disease by cardiac computed Tomography. Circulation, 114(16), 1761-91.

Liu-qiang, L.v., Yang-zhang, T., Shi-qiang W., Yi-min, X., Ling, g., and Xun-min, C. (2017). Research on the Clinical Phenotype of Coronary Heart Disease with Retinol Binding Protein 4, Lipoprotein-related Phospholipase A2, and the Severity of Coronary Artery Lesion. International Journal of Pharmaceutical Research \& Allied Sciences, 6(1), 107-112.

Daoud, A. S., Pankin, D., Tulgan, H., \& Floretin, R. (1963). Aneurysms of the coronary artery: Report of ten cases and review 37-8 of literature. The American Journal of Cardiology, 11(2), 22.

Demopoulos et al. (1997). The natural history of aneurysmal coronary artery diseases. Heart, 78(2), 136-41. 
Erol, C., \& Seker, M. (2012). The prevalence of coronary artery variations on coronary computed tomography angiography. Acta Radiological.

Falestti, H. L., \& Carrol, R. J. (1976). Coronary artery aneurysm. A review of the literature with a report of 11 new cases. Chest, 69(5), 630-6.

Fox et al. (2006). Guidelines on the management of stableexecutive summary. European Heart Journal, 27(11), 1341-81.

Hartnell, G. G., Parnell, B. M., \& Pridie, R. B. (1985). Coronary artery ectasia. Its prevalence and clinical significant in 4993. Patient British Heart Journal, 54(4), 392-5.

Herman, M. V., \& Gorlin, R. (1976). Clinical significant of coronary arterial extasia, Markis JE, Joffe CD, Cohn PF, Feen, Feen DJ. The Ameriacan Journal of Cardiology, 37(2), 217-22.

Kearney et al. (1995). Intravasular ultrasound approach to the diagnosis. Ge J, Liu F of coronary artery aneurysms. Ameraican Heart Journal, 130(4), 765-71.

Kosar, P., Ergun, E., Ozturk, C., \& Kosar, U. (2009). Anatomic variations and anomalies of the coronary arteries: 64-slice CT angiography appearace. Diagn Interv Radiol, 15(4), 275-83.

Kruger, D., Stierle, U., Herrmann, G., Simon, R., \& Sheikhazadeh, A. (1999). Exercise- induced myocardial ischemia in isolated coronary artery ectasias and aneurysms ("dilated coronaropathy"). Journal of the American College of Cardiology, 34(5), 1461-70.

Mangians, A., \& Cokkinos, D. V. (2006). Coronary artery extasias: Imaging functional assessment and clinical implications. European Heart, 27(9), 1026-31.

Marincek et al. (2005). Accuracy of MSCT Coronary Leschka S, Alkadhi H, Plass A, Desbiolles L, Grunenfelder angiography with 64-slice technology: First experience. European Heart Journal, 26(15), 1482-7.

Mavrogeni et al. (2004). Correlation Between Magnetic. Resonance Angiography (MRA) AND Quantitatie coronary angiography (QCA) in Ectatic Coronary Vessels. Journal of Cardiovascular Magnetic Resonance, $6(1), 17-23$.

Mollet et al. (2005). High-Resolution Spiral computed Tomography Coronary Angiography in patients Referred for Diagnostic Conventional Coronary Angiography. Circulation, 112(15), 2318-23.

Myerburge, R. J. (1991). Cardiac Arrest Due to Spontaneous Coronary Artery Dissection in a, Huikuri HV, Mllon SM, Patient with coronary Ectasia - a Case Report. Angiography, 42(2), 148-51.

Perlman, P. E., \& Ridgewey, N. A. (1989). Thrombosis and anticoagulation therapy in coronary ectasia. Clinical Cardiology, 12(9), 541-2.

Petrossians, A. A. (1993). Diffuse arterial ectasia with hypertrophic cardiomyopathy. Jpn Heart J., 34(2), 235-8.

Ramappa, P., Kottam, A., Kuivanemi, H., \& Thatai, D. (2007). Coronary artery extasia- Is it time for a reappraisal? Clinical Cardiology, 30(5), 214-7.

Safi et al. (2009). Extrinsci compression of left Main Coronary Artery by the Pulmonary Trunk Secondary to Pulmonary Hypertension Documented Using 64-Slice Multidetector Computed Tomography Coronary Angiography. Clinical Cardiology, 32(8), 426-8.

Satoda, M., Tatsukawa, H., \& Katoh, S. (1998). In a 26-year-old man, Sudden Death due to Rupture of Coronary Aneurysm. Circulation, 97(7), 705-6.

Sharma et al. (1990). Coronary arteriographic profile in young and Indian ptients with ischaemic heart disease; a comparative study. Indian Heart J., 42(5), 365-9.

Suzuki et al. (1994). Coronary spasm in patients with. Coronary ectasia. Catheterizaion and Cardiovascular Diagnosis, 32(1), 1-7.

Sway et al. (1983). Aneuysmal coronary artery disease. Circulation, 67(1), 134-8.

\section{Copyrights}

Copyright for this article is retained by the author(s), with first publication rights granted to the journal.

This is an open-access article distributed under the terms and conditions of the Creative Commons Attribution license (http://creativecommons.org/licenses/by/4.0/). 